\title{
Epistemologia do turismo: escolas teóricas e proposta crítica
}

\author{
Epistemology of tourism: theoretical schools and critical proposal
}

\section{Epistemología del turismo: escuelas teóricas y propuesta crítica}

\author{
Alexandre Panosso Netto ${ }^{1}$ \\ Marcelino Castillo Nechar ${ }^{2}$
}

\begin{abstract}
Resumo: $\mathrm{O}$ objetivo do estudo é discutir e problematizar o tema da epistemologia aplicada ao turismo. 0 artigo aborda a definição do termo epistemologia, o problema da construção do conhecimento em turismo, as escolas teóricas existentes e propõe a teoria crítica aos estudos turísticos. O avanço na produção científica do conhecimento em turismo, apesar de seu crescimento nos últimos anos, continua sendo um tema menosprezado. É considerado tema complexo, devido à necessidade de uma sólida reflexão filosófica e porque parece ter pouca aplicação prática, sendo extremamente teórico. O procedimento seguido é uma revisão crítica do termo epistemologia, com o propósito de analisar sua posição cientificista. Busca reconhecer as escolas que marcam a tendência analítica e a que se contrapõe a ela, a tendência histórica. A proposta aponta para o desenvolvimento de fundamentos críticos reflexivos, apresentando a teoria crítica como uma opção de construção transformadora da realidade e do conhecimento do turismo.
\end{abstract}

Palavras-chave: Epistemologia; Teoria crítica; Teoria do turismo; Conhecimento turístico.

Abstract: The aim of this paper is present, discuss and problematize the issue of epistemology applied to tourism. The paper discusses the problems in the construction of knowledge of tourism, and theoretical schools, and a proposed critical epistemology. Progress in the scientific production of knowledge in tourism, referring to epistemology, despite its growth in recent years, remains an issue that can be considered neglected or very complex due to the need for a strong philosophical reflection, with little application in practical life, by the claim of achieving scientific rigor of analytic epistemology. The procedure is a critical review of the term epistemology to discriminate the scientistic position of the term and the other schools recognize influencing this trend (analytical) and those opposed to it (such as historical), to no effect misrepresent its meaning in the humanities and social sciences, but particularly in tourism. The proposal relates to the development of reflective critical foundations, based on critical theory, as a build option to transform the reality and knowledge of tourism.

Keywords: Epistemology; Critical Theory; Tourism theory; Tourism knowledge. Universidade de São Paulo (USP), Brasil. E-mail: panosso@usp.br
Universidad Autónoma del Estado de México. Facultad de Turismo y Gastronomía de la
Universidad Autónoma del Estado de México- UAEM. E-mail: marcanec62@hotmail.com 
Resumen: El objetivo de este trabajo es presentar, discutir y problematizar el tema de la epistemología aplicada al turismo. El documento analiza los problemas en la construcción del conocimiento del turismo y las escuelas teóricas en él, bajo una propuesta de epistemología crítica. El progreso en la producción científica de conocimiento en el turismo, en referencia a la epistemología, a pesar de su crecimiento en los últimos años, sigue siendo un problema que puede ser considerado desatendido o muy complejo debido a la necesidad de una sólida reflexión filosófica, con poca aplicación en la vida práctica, por la pretensión de alcanzar el rigor científico de la epistemología analítica. El procedimiento es una revisión crítica del término epistemología para discriminar la posición cientificista. Al respecto, se reconocen escuelas que influyen en esta tendencia (analítica), pero también otras que se oponen a esa (como la histórica), sin efecto par tergiversar su significado en las humanidades y las ciencias sociales, pero particularmente en el turismo. La propuesta se refiere al desarrollo de los fundamentos crítico-reflexivos, a partir de la teoría crítica, como una opción de construcción para transformar la realidad y el conocimiento del turismo.

Palabras- clave: Epistemología; Teoría Crítica; Teoría del turismo; Conocimiento turístico.

\section{INTRODUÇÃO}

A epistemologia é tema relativamente novo no cenário de investigação do turismo, porém vem se intensificando na atualidade com crescente bibliografia, tal como a produzida por Leiper (1981, 2000), Comic (1989), Centeno (1992), Spode (1993), Tribe (1997, 2000 e 2004), Beni (1998), Phillimore e Goodson (2004), Panosso Netto (2005), Castillo Nechar e Lozano Cortés (2006), Ateljevic, Pritchard, e Morgan (2007) e Darbellay e Stock (2012) entre outros. Disciplina fundamental para o estabelecimento dos alicerces científicos de qualquer campo de estudos, a epistemologia, em turismo, ainda é vista como tema complexo, exótico, teórico, filosófico e com pouca aplicabilidade. Por isso tudo, seguida vezes é menosprezada pelos científicos da área turística, conforme comprovou o estudo de Castillo Nechar, Tomillo Noguero, e García Gómez, (2010).

De acordo com Tribe (1997, p. 639) a epistemologia em turismo é importante por dois motivos, primeiro porque "promove uma revisão sistemática do que é o legítimo conhecimento turístico" [...] e segundo porque "ainda não há acordo sobre o mapa ou as fronteiras dos estudos turísticos". Acrescenta-se que outro ponto importante da epistemologia é que ela não permite que os estudiosos se deixem levar pelas ideias hegemônicas sobre o turismo que buscam conservar a ordem e o progresso atual de seu desenvolvimento. Ou seja, praticar a epistemologia é buscar a reflexão crítica que tem por fim revelar e descobrir um mundo no qual a desigualdade, os problemas humanos e do meio ambiente, por exemplo, são parte de uma ordem funcional e estrutural que incide no turismo e também em seu conhecimento produzido. Além disso, a epistemologia é importante para que se possa explicar como se pensa o turismo e assim se faça a definição entre o falso e o verdadeiro, entre a verdade e o erro, ainda que esta discussão seja de todas as maneiras elevada e complexa.

O objetivo do artigo é discutir e problematizar o tema da epistemologia aplicada ao turismo. Serão apresentadas e analisadas algumas compreensões que os estudiosos do turismo 
até o presente momento têm da epistemologia. Serão identificadas linhas teóricas que se valem do positivismo, da fenomenologia, do marxismo, do racionalismo e da hermenêutica. Por fim se propõe a teoria crítica como alicerce na construção do conhecimento turístico. Pretende-se compreender o papel das visões e propostas que repaginam o discurso economicista e produtivista oficial de turismo e por fim propor uma visão reflexiva da epistemologia do turismo, com elementos que levem à produção de conhecimentos críticos. A metodologia está baseada na revisão crítica sobre os textos que foram selecionados. Tais textos são exemplos das correntes principais analisadas. Outros autores e obras poderiam ter sido incluídos, porém os que são citados estão em número suficiente para a compreensão e reflexão pretendidas. $A$ análise esteve amparada na teoria do conhecimento e na própria epistemologia aplicada ao turismo.

\section{CONCEITO DE EPISTEMOLOGIA}

Umas das definições clássicas de epistemologia propõe que se trata do estudo do conhecimento, e sua origem está no grego (episteme $=$ conhecimento + logia= estudo). Também é nomeada gnosiologia, filosofia do conhecimento, crítica do conhecimento e teoria do conhecimento. Lalande (1999) considera a teoria do conhecimento como a parte introdutória da epistemologia, e por isso sua auxiliar indispensável. Para esse autor, teoria do conhecimento seria o "estudo da relação que o sujeito e o objeto mantêm entre si no ato de conhecer" (1999, p.1128). Porém, aponta que dependendo do idioma e até da região, os termos podem ou não serem intercambiáveis, assim, "a distinção que se faz em francês entre epistemologia e teoria do conhecimento (gnosiologia) seria sem dúvida muito útil, mas não é usual nem em italiano nem em inglês" (Lalande, 1999, p.313).

Segundo Abbagnano (1998), em italiano o termo mais usado é gnoseologia e em alemão Erkenntnistheorie, sendo que os vários termos têm o mesmo significado. Nos idiomas alemão, espanhol, inglês, francês e português o termo epistemologia também é sinônimo de teoria do conhecimento. Parece existir uma sinonímia entre epistemologia e filosofia da ciência, mas não. $O$ termo epistemologia, no panorama cientificista, aparece a partir do século XIX. "A palavra epistemologia, que literalmente significa teoria da ciência, é de recente criação. Se a palavra é nova, o que designa também o será" (Blanché, 1973, p.5). A palavra epistemologia, mesmo sendo nova no vocabulário científico, já estava entre os antigos filósofos gregos que diferenciavam episteme de doxa.

Para Runes (1981, p.183) o termo epistemologia se assume como "... O ramo da filosofia que investiga a origem, estrutura, métodos e validação do conhecimento,...". De sua parte, Foulquié e Saint-Jean (1962, p.223) afirmam que "A epistemologia é a disciplina que trata os problemas filosóficos postos pela ciência,...". Abbagnano (1998, p.183), ao contrário, afirma que o termo não indica uma disciplina como a lógica, a ética ou a estética, mas sim "um modo de tratar um problema nascido de um pressuposto filosófico específico". Percebe-se, portanto, que existe certa dúvida se a epistemologia constitui-se uma disciplina filosófica ou não. 
Japiassu (1979, p.16) definiu epistemologia como "o estudo metódico e reflexivo do saber, de sua organização, de sua formação, de seu desenvolvimento, de seu funcionamento e de seus produtos intelectuais. Para isso a epistemologia necessita reflexão, mas nem toda reflexão sobre o conhecimento produzido traz consigo a epistemologia. Para Bunge (1980, p.12-3), a epistemologia é útil se satisfizer às seguintes condições: refere-se à ciência propriamente dita; ocupa-se de problemas filosóficos que se apresentam de fato no curso da investigação científica ou na reflexão sobre os problemas, métodos e teorias da ciência; propõe soluções claras para tais problemas, em particular soluções consistentes com teorias rigorosas e inteligíveis, bem como adequadas à realidade da investigação científica; é capaz de distinguir a ciência autêntica da pseudociência, a investigação profunda da superficial, a procura da verdade da procura de temas simples; é capaz de criticar programas e mesmo resultados errôneos, assim como sugerir novos enfoques promissores.

A epistemologia estuda a origem do conhecimento e seu desenvolvimento, ampliando a reflexão para sua validade. Um dos fundadores da teoria do conhecimento foi Immanuel Kant, em sua obra "Crítica da razão pura" (1781 [2003]). Seu método foi denominado transcendental, que não investiga a origem psicológica do conhecimento, mas sim sua validade lógica; não quer saber como surge o conhecimento, mas sim como ele e possível e sob quais fundamentos repousa (Hessen, 2003).

As questões que a epistemologia clássica se propõe a responder são vastamente conhecidas, e entre elas estão, segundo Steup (2011): “Quais são as condições necessárias e suficientes do conhecimento? Quais são suas fontes? Qual é sua estrutura e quais são seus limites? [...] Como devemos compreender o conceito de justificação ${ }^{3}$ O que justifica as crenças justificadas? A justificação é interna ou externa à própria mente?". Portanto, "a teoria do conhecimento [...] é uma interpretação e uma explicação filosóficas do conhecimento humano" (Hessen, 2003, p.19). Para Audi, a epistemologia é o "estudo da natureza do conhecimento e a justificação, e, especificamente, o estudo de a) suas características definidoras, b) suas condições substantivas e c) os limites do conhecimento e a justificação" (Audi, 2004, p.292).

No século XX a epistemologia teve avanços, e configurou algumas escolas temáticas. Para Bombassaro (1992), foram duas as principais tendências epistemológicas no século XX. A primeira é a tendência analítica, também conhecida como tendência analítica da ciência, filosofia analítica da ciência ou filosofia linguística, que adota a posição do empirismo lógico, representado por filósofos que tinham relação ou faziam parte do Círculo de Viena, entre eles Ernest Mach, Gottlob Frege, Alfred Whitehead, Rudolf Carnap, Alfred Tarski, Bertrand Russell, David Hilbert e Ludwig

\footnotetext{
${ }^{3}$ O conceito de justificação autoriza a crença num conhecimento. Segundo Lalande (1999, p.602) justificação é “Ato de justificar-se, ou de se justificar, quer dizer, primitivamente de tornar justo ou fazer-se justo [...]; depois, por enfraquecimento do sentido primitivo, se diz de todo ato pelo qual se refuta uma imputação ou até pelo qual a ultrapassamos, ao mostrar que se está no direito (quer moral, quer lógico), de o fazer, que temos razão para dizer o que dissemos, ou de fazer o que fizemos. Malebranche chamou especialmente juízos ou raciocínios de justificação às aqueles pelos quais damos razões intelectuais para apoiar os nossos sentimentos, razões boas ou más, mas em todo caso encontradas posteriormente."
} 
Wittgenstein, e pela filosofia de Karl Popper. A segunda é a tendência histórica, ou nova filosofia da ciência, que surge com críticas à tendência analítica e como uma nova opção epistemológica, representada por Thomas Kuhn, Imre Lakatos, Paul Feyerabend, Norwood Russell Hanson, Stephen Toulmin (todos da nova filosofia da ciência, influenciados por Karl Popper); Gaston Bachelard, Georges Canguilhem e Michel Foucault (que pregavam a negação da tendência analítica); Theodor W. Adorno e Jürgen Habermas (que propunham reflexões da Escola de Frankfurt).

O termo epistemologia será empregado em sentido literal: discurso (logos) sobre a ciência (episteme) (Miguélez, 1977, p.7); mas será redimensionado com a reflexão filosófica onde episteme = discurso que em seu discorrer produz uma reflexão filosófica-empírica não somente de crítica de conteúdos, mas também de conteúdos críticos, com novos sentidos e significados, a fim de transformar positivamente o problema em questão (Castillo Nechar, 2011). Porém, não se deve esquecer que o termo epistemologia às vezes se refere a uma teoria geral do conhecimento, e outras a uma teoria regional do conhecimento (Abbagnano, 1998).

\subsection{Duas tendências da epistemologia do século XX: analítica e histórica}

\subsubsection{Tendência analítica}

A tendência analítica da epistemologia tem como princípio a filosofia empirista e positivista, que afirma que o conhecimento só é possível se partir da experiência com o que é imediatamente dado. Para isso, os autores desta tendência usam a análise lógica da linguagem como método filosófico (Bombassaro, 1992). Neste quesito evidencia-se a influência do Tratactus Lógico-Philosophicus (1921 [2008]), estudo maior de Ludwig Wittgenstein.

Stich (1998, p. 106) discorre sobre este termo:

Eu proponho usar o termo epistemologia analítica para denotar qualquer projeto epistemológico que leva à escolha entre concorrentes regras de justificação ou critérios concorrentes de acertos para ligar à análise conceitual ou linguística. Não pode haver dúvida de que uma parte substancial dos escritos epistemológicos publicada em inglês no último quarto de século tem sido epistemologia analítica.

Ou seja, para este autor grande parte da teoria do conhecimento em inglês segue essa linha, sendo, portanto, fortemente baseada no positivismo e na experiência, temas que são vastamente divulgados nas hard sciences.

O Círculo de Viena, oficialmente fundado em 1929, era formado por estudiosos de diversas formações, entre físicos, matemáticos, filósofos e lógicos, e buscava construir uma filosofia científica, tendo como pressuposto a rejeição a tudo o que era considerado especulação, tal como o idealismo e as "correntes filosóficas atentas a distinguir entre ciências naturais e ciências culturais ou ciências naturais e ciências do espírito" (Mora, 1964, p.906). Os membros do grupo 
usavam a indução como teoria científica - "a teoria de que as ciências sociais naturais eram as ciências indutivas e a indução era um processo de estabelecer ou justificar teorias através de observações ou experiências repetidas" (Popper, 2008, p.114).

O objetivo do Círculo de Viena era claro: construir uma linguagem científica e buscar uma concepção científica do mundo. Seria necessária a "superação da metafísica pela análise lógica da linguagem" (Branquinho, Murcho e Gomes, 2006, p. 343), mas também a reconstrução lógica dos conceitos científicos e o uso da verificabilidade dos conceitos (que mais tarde foi superado pelo conceito da falseabilidade de Karl Popper em seu livro Logik der Forschung, de 1934). Essas teses do Círculo de Viena foram decisivas para prover a epistemologia com o rigor metodológico para a investigação (Bombassaro, 1992).

Para Karl Popper (2003) os três principais problemas da epistemologia eram: 1. A lógica da investigação (negação total à indução); 2. O critério de demarcação (negação do critério de verificação e introdução do critério de falseabilidade); e 3. A objetividade científica (mesmo destacando a necessidade da objetividade, esse autor afirmou que existe um fundamento empírico na ciência).

A tendência analítica teve seus princípios no empirismo e no positivismo. Quando Karl Popper propôs que o critério de demarcação nas ciências fosse a falseabilidade, e não a verificação ou a confirmação, a tendência ganhou novo fôlego e ocorreu sua renovação. As novas ideias trazidas por Popper configuram o racionalismo crítico e colocam esse autor numa posição central do debate. Ao mesmo tempo em que defende a filosofia empirista, ele faz a crítica fundamental ao método indutivo e ao positivismo do grupo de Viena. Popper, portanto, de um lado critica, e de outro oferece novos conceitos para o Círculo de Viena seguir vivo. Com a falseabilidade acabava de ser criada uma epistemologia negativa, a qual afirmava que somente se uma teoria fosse possível de ser refutada, é que seria científica. Sua afirmação diz: "deve ser possível refutar, pela experiência, um sistema científico empírico" (Popper, 2003, p.42). Percebe-se, portanto, que "o conhecimento, ao ver de Popper, é de natureza provisória - e permanentemente de natureza provisória. Em nenhum momento há condições para demonstrar que aquilo que sabemos é verdadeiro e é sempre possível que o sabido se revele falso" (Magee, 1974, p. 32). Essa posição teórica "implicava que as teorias científicas, se não são falsificadas, permanecem para todo o sempre hipóteses ou conjecturas" (Popper, 2008, p.114). Estava claro naquele momento que as teorias científicas são provisórias. Por melhor que sejam, podem ser refutadas (falseadas), dando lugar a uma nova teoria mais robusta, mais próxima da verdade, que diga mais e mais sobre o tema analisado. Esse ponto de vista muda drasticamente o pensamento científico, pois de um acúmulo de conhecimentos com teorias que se somam, passa-se ao avanço científico pela substituição de uma teoria por outra.

Com essas posições, Popper foi o crítico mais contundente do positivismo lógico e da análise linguística, ambos amparados pela filosofia de Wittgenstein, e que também eram fundamentos teóricos do Círculo de Viena. Isso ele mesmo assumiu sua postura crítica quando afirmou que o positivismo lógico está morto e pergunta "quem o matou?", ao que reponde: 
"receio ter que admitir a minha responsabilidade. No entanto, não o fiz de propósito" (Popper, 2008, p.126).

\subsubsection{Tendência histórica}

A partir da crise da tendência analítica da epistemologia, surge a tendência histórica que se manifesta em estudos publicados a partir dos anos 1950 e que se intensificaram nos 20 anos seguintes. O caminho seguido foi a incorporação de reflexões sobre pontos não abordados na tendência analítica, tais como os elementos históricos e a revalorização da metafísica e da ontologia (Bombassaro, 1992). Mark Wartfsky afirma o seguinte: “O objetivo ou projeto da epistemologia histórica é descrever a atividade humana na qual qualquer conhecimento é adquirido - seu gênesis, seu desenvolvimento e suas formas específicas ou modelos, na ciência e na arte." (apud Dolling, 2003, p. 35-6).

Os principais estudos desta tendência foram Patterns of discovery: an inquiry into the conceptual foundations of science (1958), de Norwood Russell Hanson, para quem o cientista utiliza o raciocínio indutivo na busca de solução aos problemas propostos e sugere que quem faz a descoberta é o homem que vê algo que outros não viram antes dele. Neste estudo aponta que não se pode separar a observação da interpretação, sem mudar as suas características. Em The structure of scientific revolutions (1962[2006]), de Thomas Kuhn, está a teoria de que as ciências avançam em saltos, em rupturas, criando e superando paradigmas em seu seio. De imediato Kuhn foi visto como um grande crítico das ideias de Popper. History of science and its rational reconstruction (1970), de Imre Lakatos, que aceita as ideias de Popper e propõe o falseasionismo sofisticado, no qual afirma que as teorias não são falseáveis por experimentos, mas sim por outras teorias em grupos de investigação. Human understanding (1972), de Stephen Toulmin, que critica Kuhn e propõe um modelo próprio de mudanças conceituais que foi comparado ao modelo evolutivo de Darwin, pois nele estão expostos os processos de evolução e de seleção das teorias. Against method (1975), de Paul Feyerabend, expõe sua teoria do anarquismo metodológico, segundo o qual o problema da ciência não seria o método, pois não há um método, mas sim vários. Para ele, em ciência, a única metodologia é o tudo vale (anything goes). Assim, sua crítica à ciência unificada é clara. Tais obras caracterizam a diversidade de abordagens desta linha.

Os novos críticos da epistemologia analítica afirmavam que ela se trata de uma filosofia simplista, pois está preocupada somente com a linguagem, a escrita, o pensamento lógico, seus enunciados, e esquece que a ciência é feita por homens, e que eles também influenciam a produção do conhecimento. A partir desta crítica, as percepções, os pré-conhecimentos dos cientistas, portanto, a história de cada um, voltam a ser considerados. O desenvolvimento da ciência passou a ser visto com outros olhos. Pois, de uma posição imutável, a histórica da ciência passa agora a ser importante. Neste sentido, os estudos de Kuhn (2006) são fundamentais, pois mostram como a ciência avança em saltos, rupturas, e muda também a forma de agir e pensar dos cientistas. 
Imre Lakatos também faz crítica ao falseasionismo (falseabilidade) de Popper e da tendência analítica. Baseando-se em exemplos da ciência, mostrou a impossibilidade deste conceito e afirmou que os próprios cientistas não o utilizam. Com suas reflexões buscou mostrar que a própria história da ciência falseia o falseasionismo popperiano (Borges, 1996). Além disso, a tendência histórica busca valorizar a metafísica, pois a obra de Kuhn também apresentou vários conceitos metafísicos na busca da caracterização do termo central de seu estudo, o paradigma.

Percebe-se que a tendência analítica é cientificista, ou seja, prega "a ideia de que a ciência faz conhecer as coisas tais como elas são, resolve todos os problemas reais e é suficiente para satisfazer todas as necessidades legítimas da inteligência humana" (Lalande, 1999, p.160). Somase a isso a ausência do pensamento divergente nesta corrente - pois tudo levava a um método científico único - além de não ser favorável à multiplicidade de ideias. Por outro lado, está evidente que a tendência histórica clama pelos erros e acertos, no qual a aprendizagem também aconteceria com os próprios erros dos cientistas. De todas as formas, na atualidade esse debate sobre a teoria do conhecimento e suas vertentes e tendências ainda não se esgotou. Alguns dos principais cientistas que se ocupam com o tema são Humberto Maturana (1990 e 2004 [este último com Varela]), Edgar Morin (1996, 1999), Larry Laudan (2011), Mário Bunge (1974, 1980, 1997) e Boaventura de Souza Santos (2009 [com Maria Paula]).

\section{ESCOLAS EPISTEMOLÓGICAS ATUAIS DO TURISMO}

Caracterizar as escolas epistemológicas atuais do turismo não é tarefa simples devido a multiplicidade de abordagens dos mais conceituados autores. Optou-se por analisar somente as escolas atuais e com maior destaque no meio acadêmico. A formação de comunidades acadêmicas, no sentido que de Kuhn (2006) apresentava, em turismo caracteriza-se não somente pela criação de grupos de pesquisadores em torno de um tema, mas também por fundamentar a unanimidade do conhecimento por aqueles que partilham o interesse em um tipo de investigação sobre certos pressupostos e procedimentos.

Algumas dessas comunidades acadêmicas não podem ser delimitadas espacialmente e nem temporalmente, pois se existiam investigadores mono-disciplinares nos anos de 1940 a 1970, também existiam os que buscavam estudos holísticos. Se nos princípios dos estudos turísticos havia os estudos mais focados em temas específicos, também existiam os que o abordavam de uma forma mais geral.

As comunidades acadêmicas de turismo não são reconhecidas como vanguardistas na produção sistemática do conhecimento em questão, devido ao fato de que se crê que não formam uma rede distinta e tentem a ser independentes e atomizadas (Tribe, 1997, 2010). Tudo isso deu lugar para o aparecimento de paradigmas de turismo, se se pode entendê-los como "realizações científicas universalmente reconhecidas que, durante certo tempo, proporcionam modelos de problemas e soluções a uma comunidade científica" (Kuhn, 2006, p.13). Esses paradigmas, entre várias outras crenças científicas, são evidenciadas também nas escolas temáticas de turismo que 
foram identificadas, sendo elas: a positivista (cientificista), a sistêmica, a marxista, a fenomenológica, a hermenêutica e a teoria crítica. Destaca-se que a visão positivista foi por muito tempo um dos paradigmas científicos no turismo. As outras perspectivas que surgiram após ela foram tentativas de superação de seus pontos deficientes (Panosso Netto, 2011).

\subsection{Positivismo}

O positivismo analisa o turismo com a métrica clássica, com a necessidade de dados claros, metodologias estabelecidas, objetos de estudos definidos. O positivismo propõe a existência de um método que oferece segurança e certeza na investigação. Nesta corrente, "até certo ponto, as investigações sobre o método tornaram mais rigorosas e cautelosas as afirmações sobre a validade do conhecimento produzido na investigação científica" (Bombassaro, 1992, p.50). positivismo lógico identificou um método segundo o qual somente por ele poderiam ser descobertas verdades; assim, todos os enunciados deveriam ser postos à prova por este método, que já havia estabelecido critérios para dizer que eram ou não significativos (Panosso Netto, 2011). Ocorre com essa visão a exclusão da historicidade da ciência, considerando que a história seria apenas um conjunto de fatos sem importância científica. As críticas foram duras, e muitas. Bombassaro (1992, p.51) analisando o positivismo de forma geral, assim se expressou: “[...] neste sentido, ao pretender buscar os meios seguros para garantir a indubitabilidade do conhecimento, o positivismo lógico identificou a racionalidade com um conjunto de algoritmos, cuja função consistiria em dispensar o próprio investigador da tarefa e do compromisso de tomar decisões".

Essa perspectiva científica vai se refletir nos estudos turísticos em posições teóricas que buscam desprovê-los de caráter científico, de que não poderá ser uma ciência. Esta é a posição de Cooper, Fletcher, Gilbert e Wanhill (1993, p.1), quando afirmam que "por enquanto o turismo se constitui num domínio de estudo, no momento em que ele não tem um nível de sustentação teórica que lhe permitiria se tornar uma ciência""; e Tribe (1997, p. 643), que amparado nos estudos desenvolvidos por Hisrt (1965, 1974, 1993), afirma:

Os conceitos de turismo não formam uma rede distinta. Sua única ligação é o objeto de seu estudo, ou seja, o turismo. Eles não formam uma estrutura teórica coesa. Por este motivo, não há uma estrutura lógica distinta para os estudos turísticos. Os estudos turísticos, por si só, não oferecem uma distinta e estruturada forma de analisar o mundo, assim como diz a física.

Ao analisar o sistema turístico proposto por Leiper (1981), Tribe (1997, p.646) afirma que apesar de ele ser "um mapa útil das dimensões do turismo, ele dificilmente constitui uma teoria unificadora do turismo". Ou seja, Tribe (1997) evidencia que acredita que o turismo deva ter uma

\footnotetext{
${ }^{4}$ No original em inglês está a palavra "discipline", porém o termo correto em português, é "ciência", pois é isso o que os autores estão se referindo. A simples tradução de "discipline" por "disciplina", em português, não seria correta, pois em inglês "disciplina" também significa ciência, fato que não ocorre em português. (Nota dos autores).
} 
teoria unificadora, sendo esta outra característica da visão positivista que busca unificar o conhecimento. A Organização Mundial do Turismo (2001) também é adepta desta perspectiva, sendo, inclusive, uma de suas principais divulgadoras.

Logicamente que o estudo do turismo não pode ser visto com a perspectiva da física, nem seria possível criar uma estrutura lógica e formar um arcabouço teórico ao modo das ciências exatas. Os autores desta corrente partilham da visão positivista de que o turismo não é uma ciência, pois não pode alcançar os patamares estabelecidos pelo classicismo científico. Obviamente que o conceito de ciência destes autores é das ciências clássicas. A visão de Cooper et al. (1993) e de Tribe (1997) é contrária à perspectiva de Defert (1966), Alcalde Inchausti (1967), Jovicic (1975), Fernández Fúster (1978), Beni (1998) e Jafar Jafari (2001). Este último já sustentava que o turismo era uma ciência por sua doutrina sistematizada e lógica validada na prática da atividade e que esse setor havia adquirido o status de ciência devido a uma ampla gama de definições, conceitos, temas, problemas, perspectivas e instituições que o investigavam e o promoviam.

Assim, o positivismo apresenta as seguintes diretrizes que são aplicadas aos estudos turísticos: 1. Fundamento na ciência clássica como base do desenvolvimento da atividade. 2. Os avanços tecnológicos foram os grandes propiciadores do nascimento do turismo contemporâneo. 3. O estudo do turismo não pode ser elevado à categoria de ciência ou disciplina científica. 4. 0 turismo constitui-se num avanço da sociedade como parte de um valor universal. 5. Estudos estatísticos, que apresentam cifras dos deslocamentos de pessoas pelo mundo, são provas de que o fenômeno turístico está crescendo. 6. A grande quantia de dinheiro gerada pelo turismo confirma o sucesso da atividade. 7. Quando mais passa o tempo, mais o turismo cresce.

A visão positivista muitas vezes se reflete na universidade, que passa a ser rígida, operacional, que treina e adestra, limitando o pensar. No entanto, é necessário romper com esse modelo, pois o aporte ao conhecimento do turismo, pelas comunidades acadêmicas, se pode observar através do tempo e por uma série de passos que diferenciam o trabalho de qualquer comunidade de investigadores: reconhecimento das anomalias; período de insegurança; desenvolvimento de grupos de ideias alternativas; identificação de escolas de pensamento; dominação de novas ideias; crítica atual sobre o tema discutido e; consciência da existência de pontos frágeis do pensar turístico.

Para uma correta postura sobre o método em turismo, se deveria levar em consideração que "a questão do método em turismo segue a dinâmica das ciências nas quais o turismo é objeto de estudos" (Dencker, 1998, p.28). Assim, propor a criação e utilização de apenas um método é inviável para a análise completa do fenômeno.

\subsection{Sistemismo}

O sistemismo, ou teoria geral de sistemas, teve como um de seus principais pioneiros e criadores o biólogo Ludwig Von Bertalanffy (1901-1972). Esse autor percebeu que os seres vivos não eram estudados coerentemente pelo mecanicismo e que a biologia da época (décadas de 
1920-1930) estava negligenciando a organização desses seres (Vasconcellos, 2002). Para ele, essa organização era o fenômeno essencial da vida. A partir da visão de que tudo poderia ser analisado como sendo e fazendo parte de um sistema, surgiu a teoria geral de sistemas. Leiper (2000, p. 570) explicou o enfoque dessa teoria:

A finalidade distinta da teoria geral de sistemas é lidar com qualquer coisa ou qualquer ideia que pareça complexa. $\mathrm{O}$ objetivo é reduzir a complexidade. $\mathrm{O}$ valor é que depois de a complexidade ter sido reduzida, as coisas e ideias tornam-se mais fáceis de serem compreendidas, analisadas e gerenciadas. A estratégia para alcançar tal objetivo é, a grosso modo, quebra [dividir] um todo (coisa ou ideia) em seus elementos, e então identificar os atributos essenciais dos elementos para ver como eles estão conectados.

Beni (1998) apontou que qualquer sistema deve conter meio ambiente, elementos ou unidades, relações, atributos, entrada, saída, realimentação e modelo. Além disso, definiu sistema como "um conjunto de partes que interagem de modo a atingir determinado fim, de acordo com um plano ou princípio; ou conjunto de procedimentos, doutrinas, ideias ou princípios, logicamente ordenados e coesos com intenção de descrever, explicar ou dirigir o funcionamento de um todo" (Beni, 1998, p.23).

A teoria geral de sistemas se tornou um paradigma nos estudos turísticos, principalmente na América Latina, com especial enfoque na Argentina, Brasil e México (Lohmann, Panosso Netto, 2008). Segundo Beveridge (1981), as principais características de um sistema são: interação harmônica entre seus componentes; um sistema é mais do que a soma de suas partes; se um dos elementos do sistema não funciona, compromete o funcionamento de todo o sistema; os sistemas abertos se relacionam com outros sistemas; os sistemas funcionam em relação com seu ambiente; a maioria dos sistemas sofre coerções internas e externas; os sistemas na biologia, na sociologia e na indústria tendem a alcançar seu equilíbrio (homeostase).

O primeiro autor a transportar e aplicar o pensamento sistêmico ao turismo foi Cuervo (1967). Para ele o turismo seria um grande sistema, composto de outros conjuntos menores: meios de comunicação, estabelecimentos de hospedagem, agências de viagens, guias de turismo, estabelecimentos que oferecem alimentos e bebidas, estabelecimentos que oferecem bens de consumo aos viajantes, fabricantes de produtos típicos vendidos aos turistas, e os centros de diversão. Todos os sistemas devem ter um modelo que facilite sua compreensão. O sistema de turismo mais conhecido do mundo anglosaxão é o de Leiper $(1979,1995)$, ainda que existam vários outros sistemas de turismo, tais como o de Sessa (1985), Molina (1991), Beni (1998), e o de Boullón (2002), por exemplo.

\subsection{Marxismo}

A visão marxista aplicada ao turismo tem relação com aquilo que MacCannell em 1976 apontou como "semiótica da produção capitalista". Isso significa que o turismo é impulsionado - e existe - pelos fatores econômicos de produção. Da produção de bens e serviços turísticos, surge a mais-valia, que é o excedente da produção transformado em lucro pelo empresário. 0 turismo não 
está disponível a todos. Somente aqueles que têm condições financeiras poderão pagar por ele e desfrutar do status social de ser um turista. Nesta perspectiva, o homem seria explorado pelo próprio homem.

A abordagem marxista também prega que o turismo é uma forma de imperialismo e colonialismo (Krippendorf, 1984; Nash, 1977). Os que vivem nos países mais ricos têm mais propensão às viagens do que os que vivem nos países pobres. Quando ocorrem essas viagens, então pode ocorrer uma situação de opressão. Quem viaja tem dinheiro e tempo livre, demonstrando estar em uma posição de privilégio diante de quem recebe o turista. Quem recebe está em seu tempo de trabalho e não dispõe de muitos recursos financeiros. Essa situação já foi revelada por Young (1973), quando denunciou os problemas que o turismo causa nos destinos. Este autor apresentou um cenário no qual não seria fácil eliminar os problemas do setor. Cohen (1972) também fez críticas dessa natureza. Outros grupos de autores seguiram com análises mais pontuais. O certo é que a visão marxista contribui para uma visão mais crítica da atividade, ainda que muitas vezes seja radical.

Para entender como pensam alguns dos pesquisadores que enfocam seus estudos no marxismo, opta-se por reproduzir a seguinte passagem de Mullor e Blázquez (2011, p.7):

\begin{abstract}
Muitos cientistas do turismo adotam enfoques acríticos e legitimadores para com este setor. Mas atrás disso se escondem deteriorações sociais, ambientais e econômicas que devem ser analisadas e discutidas publicamente. Longe de produzir os efeitos prometidos em termos de desenvolvimento e bem estar social, sua expansão sob a lógica do capital supõe uma nova fonte de conflitos e contradições para as sociedades nas quais está. 0 turismo não é uma panaceia, mas sim atua como um placebo. Frente à publicística do setor turístico, entendemos que nosso dever como cidadãos e cientistas sociais é promover uma análise rigorosa e com ponto de vista, orientada para a defesa dos interesses da maioria da população, sobre a qual supõe a turistificação de nossas sociedades.
\end{abstract}

Esta corrente tece críticas ao turismo como atividade de burgueses e industriais. Também considera que o turismo nasceu a partir do surgimento do capitalismo e que são as leis econômicas que coordenam como, quando e para onde os turistas devem viajar. Entre autores que fazem esta crítica estão Young (1973), Bonaldo (1984), Ouriques (1998), Bem (2005), Mullor e Blázquez (2011) e Jiménez (2011).

\title{
3.4 Fenomenologia
}

A fenomenologia é um movimento filosófico do século XX. Historicamente como método tem sido mais utilizado pelas áreas de enfermagem, educação, estudos da religião, management studies e psicologia existencial (Pernecky, Jamal, 2010). Um dos temas estudados por ela é a experiência humana. A partir da concepção de que a experiência também é um dos elementos principais do turismo, a fenomenologia passou a ser aplicada nos estudos sobre o turismo. A 
descrição fenomenológica baseia-se na observação e na percepção do turismo como um fenômeno altamente dinâmico, desenvolvido no tempo e no espaço por um indivíduo ou um grupo. Fenômeno turístico, portanto, seria algo que se mostra a si mesmo, tal como é, do modo que é (Panosso Netto, 2011).

A pesquisa fenomenológica "é em grande parte desconhecida na pesquisa turística" e "a pesquisa fenomenológica é altamente complexa; consome muito tempo, requer ativo envolvimento do pesquisador, atenção e conhecimento da abordagem filosófica da abordagem particular" (Pernecky, Jamal, 2010, p. 1057). A crítica oferecida por esses autores é no sentido de incentivar os estudos fenomenológicos do turismo, pois esta, segundo eles, é uma importante área.

Autores têm afirmado que as teorias não refletem de forma completa o que é o fenômeno turístico em sua essência. Até os dias atuais alguns investigadores da temática ainda se perguntam o que é o turismo, quais são seus fundamentos, suas características principais. Essas perguntas levam à busca de se compreender a essência do turismo, no sentido fenomenológico. As teorias estão mais preocupadas nas relações de consumo, as relações de mercado. Porém, o turismo envolve muito mais do que isso. No turismo estão também as necessidades, anseios e desejos humanos, bem como motivações psicológicas que são fundamentais na definição do que é e o que representa o turismo.

A fenomenologia, para esse grupo de autores, pode ajudar a criar uma teoria do turismo. Ela permite a interpretação do fato em si, ou da coisa. Com a interpretação do fato em si a fenomenologia propõe a reflexão a respeito do conhecimento acumulado sobre a temática. Lyotard $(1967$, p.8) afirma que a fenomenologia "foi de início e continua a ser uma meditação sobre o conhecimento, um conhecimento do conhecimento".

Pernecky e Jamal (2010) afirmam que a pesquisa fenomenológica aplicada aos estudos turísticos apresenta alguns desafios, entre eles o desconhecimento da teoria e a própria complexidade da fenomenologia. Para Jovicic (1988), a criação de uma teoria do turismo irá passar, necessariamente, por um estudo de sua epistemologia com base na fenomenologia.

$\mathrm{Na}$ literatura há diversos estudos de fenomenologia do turismo, entre eles Cohen (1979), Molina (1991), Masberg e Silverman (1996), Marioli (2002), Ingram (2002), Panosso Netto (2005), Caton e Santos (2007), Andriotis (2009), Szarycz (2008, 2009), Santos e Yan (2010) e Pernecky e Jamal (2010).

\subsection{Hermenêutica}

A hermenêutica trata-se de um saber orientado para a interpretação de textos. Os textos são matéria, ou assuntos de interpretação. Os textos podem ser visuais, acústicos, escritos, falados, sonoros, etc. A hermenêutica pretende ser teoria e metodologia (Conde Gaxiola, 2008), sendo inclusive considerada o novo paradigma da episteme filosófica na atualidade (Beuchot, 2003).

A hermenêutica possui várias correntes. Uma delas é a hermenêutica dialética 
transformacional, aplicada recentemente no turismo por Conde Gaxiola (2008a, 2008b) que se vale dos fundamentos de Beuchot (2003). Esta proposta visa inquirir sobre o ser humano não apenas em sentido metonímico, mas também em sentido metafórico.

Para Conde Gaxiola (2008, p.93), trata-se de um caminho que pretende romper com "a estirpe univocista, visualizada nas orientações positivistas, funcionalistas, estruturalistas e condutivistas, partidárias da explicação superficial da compreensão, da literalidade negando a poeticidade, e dos modelos das ciências exatas e da natureza, avassalando os saberes humanistas". Trata-se, portanto, de uma metodologia crítica na leitura, releitura e nova interpretação do conceito turismo.

Para os autores hermenêuticos, é importante a aplicação da hermenêutica nos estudos turísticos porque ela "proporcionaria elementos para aproximar-se de uma interpretação dos fatos turísticos, evitando os enfoques descritivos, típicos do funcionalismo turístico e do culturalismo (Conde Gaxiola, 2008, p.93); e também porque

através de seu horizonte conceitual, ofertaria instrumentos para nos aproximar das grandes temáticas do turismo. A nós parece que um tratamento hermenêutico e dialético das modalidades e práticas do tempo livre e do turismo na sociedade [...] poderia oferecer novas pautas para abordá-las de forma mais adequada, e para contribuir na tipificação do planejamento e nas políticas turísticas do Estado e na caracterização das tendências turísticas mundiais, entre outros. (Conde Gaxiola, 2008, p.93).

Pernecky e Jamal (2010) apresentaram um quadro explicativo das diferenças entre a fenomenologia de Husserl (considerado um dos criadores da corrente filosófica) e da hermenêutica de Heiddeger, que foi discípulo de Husserl, mas que mudou significativamente o aporte teórico da fenomenologia em busca da compreensão do ser no mundo (da-sein).

Outros autores que elaboraram estudos turísticos e amparados na hermenêutica foram Ferreira (2008) e Patterson, Watson, Williams, Roggenbuck (1998) e Caton e Santos (2008).

\section{EPISTEMOLOGIA CRÍTICA DO TURISMO}

A necessidade do desenvolvimento dos estudos críticos em turismo é uma consideração aceita por muitos investigadores na atualidade (Ateljevic, Pritchard, Morgan, 2007; Botterill, Gale, Haven, 2003; Castillo Nechar, Lozano, 2006; Castillo Nechar, Panosso Netto 2010; Dann, 2011; Franklin, 2004, Panosso Netto, Tomillo Noguero, Jäger, 2011; Tribe, 2008). Sobre a falta da crítica nos estudos turísticos, Tribe identificou que "uma significativa lacuna na pesquisa tem sido encontrada entre a ausência da pesquisa crítica e os vários temas significativos que requerem seus insights e orientações" e também "verificou-se que a crítica em turismo ainda é marginal em relação a todo o esforço da pesquisa em turismo (Tribe, 2008, p.253). Essa carência de crítica nos estudos leva ao resultado de que "nem toda abordagem produz conhecimentos sólidos - e com um mínimo de 'vida útil' - que servem de base para novas pesquisas" (Panosso Netto, Tomillo Noguero, Jäger, 2011, p.541). 
$\mathrm{Na}$ crise das teorias e dos estudos turísticos, foram identificados quatro momentos claros: a crise da instituição universidade; a crise na filosofia; a crise dos valores culturais, humanos, morais e éticos e; a crise dos valores históricos (Panosso Netto, Tomillo Noguero, Jäger, 2011). Portanto, torna-se imperial o desenvolvimento de estudos em turismo com a perspectiva crítica.

Mas o que significa ser crítico? É de conhecimento que a teoria crítica tem suas origens em autores como Walter Benjamin, Theodor Adorno, Herbert Marcuse, Max Horkheimer que fizeram parte da Escola de Frankfurt. Uma das preocupações à época desses autores, e até na atualidade, era propor soluções aos problemas mal resolvidos pela corrente positivista que praticamente limitada a atuação e o engajamento do investigador com a realidade investigada. A teoria crítica tem consciência de que o investigador sofre influências no desenvolvimento de sua pesquisa da sociedade, do meio acadêmico, as agências de financiamento, dos governos. Considera também que os valores morais podem influir nesta pesquisa. Portanto, a produção do conhecimento não é livre de interferência, como propunha a perspectiva positivista. Assim, "ser crítico é perceber que a pesquisa pode estar (e está), influenciada por grupos de poder" (Panosso Netto, Tomillo Noguero, Jäger, 2011, p.554).

A teoria crítica auxilia os estudos turísticos ao mostrar os interesses ocultos que direcionam as investigações e ajuda a desvelar as ideologias que se manifestam no dia a dia do fazer acadêmico. A proposta que se apresenta tem fundamentos no que propôs Castillo Nechar e Lozano (2006) e Castillo Nechar (2011), que buscam exercitar a crítica reflexiva e interpretativa do turismo mediante a construção de conteúdos críticos, e não somente a crítica a conteúdos. A crítica busca compreender, construir, interpretar e produzir um sentido novo, um novo significado do objeto de estudo em questão, pois nada é dado que não deva ser e possa ser superado, é um levar-trazer o não dito para o dito, o não enunciado para o enunciado.

A este processo de crítica soma-se o ato de interpretar. Interpretar significa mais do que a simples descrição, como uma mera construção mental. Interpretar se trata de um discurso por construir. É construir com seriedade tal que permita seguras e amplas margens de atualidade, veracidade e verossimilidade, ou seja, se trata de colocar em prática o que a razão vai construindo de forma abstrata. Assim, o ato de interpretar implica detectar certa solidez nos sentidos que os indivíduos comunicam. A busca de sentidos não é algo abstrato, mas sim social. Nesse sentido, Castillo Nechar e Lozano (2006) assinalam que não somente se está diante de uma crise dos fundamentos do conhecimento científico, senão também do filosófico, e, em geral, diante de uma crise dos fundamentos do pensamento.

Dada esta posição, é necessário resgatar o processo dedutivo e indutivo do pensar, como complemento que coimplica a construção de um saber que aspira a ser rigoroso no conhecimento do turismo. Esta proposta crítica põe em evidência muitos vícios de lógica que têm se convertido num hábito em amplos setores da vida acadêmica, e, sobretudo, denuncia a falta de racionalidade na qual se tem caído em muitos outros segmentos ao se avaliar o nível de certeza, rigorosidade e medida do conhecimento turístico nas investigações, pelo simples "uso correto" das regras metodológicas preestabelecidas, sem se buscar examinar a lógica, o significado e as implicações 
do conhecimento construído. Esta proposta crítica, reflexiva e hermenêutica na epistemologia do turismo poderia terminar postulando uma matriz epistêmica distinta, com um sistema de estabelecimento de significados e processos operativos também diferentes (Panosso Netto, 2011).

Pelo exposto, é a perspectiva da teoria crítica que pode torna-se um novo paradigma nos estudos turísticos. Além deste novo paradigma, a teoria crítica impulsiona e abre espaço para novos temas que são postos em pauta pelos investigadores de turismo, que anteriormente eram ignorados. Entre tais temas, estariam alguns dos apontados por Holden (2011), entre eles:

O reconhecimento do valor do paradigma interpretativista, pesquisa ação e abordagem participativa; pluralidade de vozes para além do mundo Anglo saxão; conceitualizações de identidade, cidadania, mobilidade; pluralidade de publicação - reconhecimento da pesquisa em ciências sociais no turismo no mundo não falante do inglês; hegemonia e poder; igualdade de direitos e turismo; bem estar e saúde; destravar os processos de dualidade em turismo - combate à pobreza ou propagação da desigualdade econômica; destruir a cultura ou renovar o orgulho cultural; destruir a natureza ou uma ferramenta de conservação; escapismo ou autenticidade; empoderamento feminino ou exploração.

O que se evidencia é que aquilo que possibilita e impele o indivíduo a construir conhecimentos não é a transposição de teorias a realidades determinadas, senão a compreensão ou criação de sentidos que não são totalmente compreendidos e criados. Assim, o processo de construção de conhecimentos turísticos deve ser desmistificado, pois não são somente "cientistas" que produzem conhecimento, já que a teoria e a prática não são processos opostos e excludentes.

Segundo Castillo Nechar (2011) não é crítica: um desentendimento entre duas visões; gosto que envolve preferências pessoais; atitude de uso diário, como expressão dos defeitos de algo. Porém, é crítica: ter a capacidade de discernir; cultivar um pensamento reflexivo interpretativo e abrangente; postura intelectual que tenta analisar e avaliar a estrutura e a coerência do raciocínio.

A proposta de ser crítico em turismo é uma proposta epistemológica, pois se trata do sentido do conhecimento em turismo e do que se sabe sobre o turismo. Os estudiosos do turismo adeptos do cientificismo tendem a valorizar a produção de conteúdos, mas nem sempre valorizam a criação de conteúdos novos e críticos. Os alunos são levados a aceitarem ideias e apenas repetir o que já foi feito no passado. Porém, essa visão já foi superada pela tendência histórica da epistemologia, que, aliás, apoia o pensamento livre, e incentiva novas ideias, valorizando os conflitos intelectuais e a própria dúvida. Uma proposta de epistemologia crítica do turismo vai levar a três ações concretas por partes dos pesquisadores, segundo Castillo Nechar (2011). Primeiro, é tirar a carga positivista da ciência que tem um interesse pragmático, mecânico-casual e funcionalista. Segundo, buscar reconhecer a concepção da ciência e da epistemologia que existe sobre a construção do conhecimento produzido. Terceiro, compreender o termo ciência, em sua dimensão ampla, a partir do vocábulo scientia, na concepção de conhecimento, prática, doutrina e erudição.

Simplesmente ter a capacidade da inteligência e do conhecimento não significa que um ser 
pensante seja crítico. Nem sequer o emprego da lógica matemática, ou da lógica linguística, conduz alguém ao patamar de ser um crítico. O ser crítico usará destes conceitos e redefinirá sua forma e seus campos de aplicação. Trará a eles e à realidade que os cerca nova compreensão por meio de novos processos de reflexão baseada na relação teoria-práxis. Práxis aqui entendida como ação contextualizada e refletida. Além disso, reavaliará os seus próprios processos mentais em busca de equívocos lógicos, filosóficos, metodológicos ou da memória.

O uso preciso da palavra crítica provém do grego крıtıkós (kritikós), que significa ser 'capaz de discernir'. Da mesma raiz grega deriva o verbo peneirar, que se refere a uma ação que separa uma coisa composta em dois grupos: os que cumprem um determinado critério e os que não cumprem. Exercitar a crítica, portanto, não é externar abruptamente uma opinião, um juízo ou ação. Implica cultivar um pensamento crítico que se observa no carácter da pessoa, cujo hábito de conduta procede a uma crítica dos dados do problema, antes de formar sua opinião ou de atuar conforme um fim.

A epistemologia crítica do turismo não implica na proposta de sistemas científicos, linguísticos, filosóficos, matemáticos, estatísticos ou metodológicos que sejam universalmente comprovados, rigorosos e válidos. Há décadas as críticas ao turismo têm mostrado as dificuldades da intelectualidade turística e do conhecimento turístico. Ou seja, as teorias até então não têm dado conta dos maiores problemas teóricos do turismo, entre os quais estão: o que é o turismo? É possível uma teoria do turismo? Quais são os limites teóricos do turismo? Como construir conhecimentos críticos em turismo? Portanto, as promessas feitas pelos teóricos do turismo ainda não foram cumpridas. Mas os grandes discursos, os grandes debates existiram em turismo. Porém, também existiu claramente uma inibição da articulação entre a crítica e o mundo teórico/prático. As novas gerações de estudantes são formadas voltadas somente para a formação profissional, técnica, sem reflexão, sem pensamento analítico.

A discussão dos fundamentos do turismo também esteve limitada pela fragmentação disciplinar dos grupos acadêmicos. Os grupos dominantes condicionaram os temas a serem discutidos, os congressos, os recursos para investigação. Isso refletiu no pouco interesse em discutir os fundamentos epistemológicos do turismo. Assim, a visão pós-moderna, turbinada com a hipermodernidade (Lipovetsky, 2005), fortaleceu o individualismo, a fragmentação do conhecimento, a ausência de utopias e de grandes discursos, o vazio existencial e deixou as várias ciências e campos de estudos humanos, entre eles o turismo, em condições meramente de medição de desempenho, operação e praticidade do mundo.

A epistemologia crítica do turismo se interessará pela transformação da realidade, com uma observação na busca de construir um mundo melhor para todos. O problema epistemológico é, portanto, captar a realidade em transformação frente a tantos conhecimentos e realidades transformadoras e em transformação. Buscará também a formação de sujeitos sociais ativos, que transformem de forma benéfica sua realidade. Sujeitos que compreendam os processos, os paradigmas, as correntes científicas e que atuem no direcionamento rumo à melhor práxis de acordo com o momento social, cultural, econômico e ambiental. 
A crítica passará a ser uma atitude de negação àquelas posições hegemônicas, que não aceitam novas atitudes e visões de mundo. Também compreenderá o turismo um fenômeno que traz muitos benefícios, mas se mal desenvolvido pode acarretar impactos negativos irreparáveis no destino e nas pessoas que ali habitam. O papel da universidade então, se torna relevante ao incentivar a crítica entre seus acadêmicos. Uma crítica que possa transformar a realidade e não apenas compreendê-la.

A partir desta visão é que as novas propostas de compreensão e significação da "realidade turística", como a hermenêutica, a fenomenologia e a própria teoria crítica, dentre outros esquemas pós-positivistas, irão permitir uma proposta crítica a realidades turísticas reconstruídas.

A universidade deve ser o espaço por excelência do desenvolvimento da crítica. Os programas de ensino ali devem ter enfoque interdisciplinar e promover o pensamento crítico em seus alunos. Os problemas devem ser abordados sobre vários enfoques e possibilidades para elevar a capacidade reflexiva e a produção de conhecimentos dos alunos. A observação, a análise, a síntese podem proporcionar a crítica transformadora.

\section{CONSIDERAÇÕES FINAIS}

A falta de visão da importância que a epistemologia tem para o turismo não se deriva do pouco tempo que ela é aplicada a este campo de estudos, mas sim, possivelmente, da falta de atenção de seus investigadores. Estes têm limites para compreender o sentido e significado que tem o produzir e construir conhecimentos na área para mais além da visão da ciência positivista e da epistemologia analítica. Da mesma forma, a ausência de tradição que revalorize a reflexão filosófica crítica na sociedade, tem sido causa de inadequadas interpretações do status que o turismo tem adquirido como disciplina de carácter científico. Ao se evitar as transposições analógicas do cientificismo como lógica de medida, rigorosidade e exatidão, poderia se avançar nesta discussão da epistemologia crítica em turismo.

A variedade de acepções - e até de sinonímias - que tem a palavra epistemologia não implica uma justificativa para assumir sem juízo crítico uma vertente filosófica-cientificista, nem uma analítica que evite transgredir discursos economicistas, produtivistas e funcionalistas. Tais discursos escondem a realidade e o conhecimento do turismo a fim de uma transformação emancipadora de estruturas e ideologia que subjugam o conhecimento e a prática do turismo. É necessário reconhecer as tradições filosóficas e o viés centrista do termo epistemologia na introdução da chamada ciência moderna e, particularmente, da filosofia da ciência que estabelece a epistemologia como um ramo da filosofia que serve a ela, a ciência moderna.

As tendências epistemológicas do século XX, tanto a tendência analítica quanto a tendência histórica, são prova de dois grupos que não estarão de acordo nem unificarão seus critérios para designar o produto final como ciência. O problema está em vários campos do saber, pois os critérios, objetos, pressupostos, problemas e metodologias são divergentes. Algo semelhante se observa em turismo. As principais escolas de pensamento buscam imitar a tradição positivista da 
epistemologia analítica e o funcionalismo alienante. O objetivo é demarcar que não será possível fazer do turismo uma disciplina científica por falta de rigorosidade, medida, e exatidão de seus critérios. Frente a isso, a perspectiva crítica emerge como um argumento, paradigma e eixo transformacional contra o objetivismo com o qual alguns desejam observar o turismo. Deve ser possível com a crítica-reflexiva superar o funcionalismo com o qual desejam alguns pesquisadores submeter a prática e o conhecimento do turismo, afim de mantê-lo em "ordem, equilíbrio e progresso".

O objetivo dos acadêmicos de turismo não é somente dar respostas ao funcionamento do turismo ou formular visões novas para estudar o turismo. O objetivo deve ser promover a transformação de sua realidade, conhecimento e prática. Para isso é vital assumir exercícios críticos, reflexivos e interpretativos que permitam reconhecer cenários novos de comportamento. Também é necessário reconhecer argumentos inovadores sobre a sua compreensão e conhecimento, procedimentos de indagação e determinação de objetos inter e transdisciplinares frente a realidades complexas, nas quais se apresenta o turismo como totalidade social.

O aporte de uma teoria crítica para uma epistemologia crítica do turismo está em assumir uma atitude que não somente denuncie, mas que também transforme a realidade onímoda do turismo. Que tenha capacidade de cultivar um pensamento reflexivo, crítico e interpretativo, que em vez de criticar conteúdos, construa conteúdos críticos do turismo, e assim conceber e possibilitar um mundo turístico melhor para todos.

\section{REFERÊNCIAS}

Abbagnano, N. (1998). Dicionário de filosofia. São Paulo: Martins Fontes.

Alcalde Inchausti, A. (1967). Prólogo a Pulido. Introducción a un análisis econométrico del turismo. Cuadernos Monográficos del Instituto de Estudios Turísticos. Madrid.

Andriotis, K. (2009). Sacred site experience. A phenomenological study. Annals of Tourism Research, 36(1), pp. 64-84.

Ateljevic, I., Pritchard, A., \& Morgan, N. (Eds.). (2007). Critical turn in tourism studies. Innovative Research Methodologies. Oxford: Elsevier.

Audi, R. (2004). Diccionario Akal de filosofía. Madrid. Akal Ediciones.

Barreto, M. (2000). Manual de iniciação ao estudo do turismo. 9. ed. Campinas: Papirus.

Bem, A. S. do. (2005). A dialética do turismo sexual. Campinas: Papirus.

Beni, M. C. (1998). Análise Estrutura do turismo. São Paulo: Senac São Paulo.

Beuchot, M. P. (2003). Hermenéutica analógica y del umbral. Salamanca: San Esteban. 
Beveridge, W. I. B. (1981). Sementes da descoberta científica. São Paulo: Tao/EDUSP.

Blanché, Robert. (1973). La epistemología. Barcelona: Oikos-Tau.

Bombassaro, L. C. (1982). As fronteiras da epistemologia. Como se produz conhecimento. Petrópolis: Vozes.

Bonaldo, O. (1984). Turismo tropical, vocação regional e estratégia imperialista. Recife: Unicap, Caderno 4, pp. 30-54.

Borges, R. M. R. Em debate: cientificidade e educação em ciências. Porto Alegre: EDIPUCRS, 1996.

Botterill, D., T. Gale., \& C. Haven (2003). A Survey of Doctoral Theses Accepted by Universities in the UK and Ireland for Studies Related to Tourism 1990-1999. Tourist Studies, 2 (3), pp283-311.

Boullón, R. C. Planejamento do espaço turístico. Bauru: EDUSC.

Branquinho, J., Murcho, D. \& Gomes, N. G. (Eds.). (2006). Enciclopédia de termos lógico-filosóficos. São Paulo: Martins Fontes.

Bunge, M. (1980). Epistemologia: curso de atualização. São Paulo: Queiroz Editor/EDUSP.

Bunge, M. (1997). Ciencia, técnica y desarrollo. Buenos Aires: Sudamericana.

Bunge, M. (1974). Teoria e realidade. São Paulo: Perspectiva.Castillo Nechar, M. (2011). Epistemología critica del turismo ¿qué es eso? Turismo em Análise, 22(300, pp. 516-538.

Castillo Nechar, M., \& Lozano Cortés, M. (2006). Apuntes para la investigación turística. Cozumel-Quintana Roo: Universidade de Quintana Roo.

Castillo Nechar, M., \& Panosso Netto, A. (2011). Implicaciones epistemológicas en la investigación turística. Estudios y Perspectivas en Turismo. 20, pp. $384-403$, Buenos Aires: CIET.

Castillo Nechar, M., \& Panosso Netto, A. (eds.). (2010). Epistemología del turismo. Estudios críticos. México: Trillas.

Castillo Nechar, M., Tomillo Noguero, F., García Gómez, F. J. (2010). Principales tendencias de la investigación turística en España y Europa. Universidad Europea Miguel de Cervantes: Valladolid.

Caton, K., \& Santos, C. A. (2008). Closing the hermeneutic circle? Photographic Encounters with the Other. Annals of Tourism Research, 35(1), pp. 7-26.

Centeno, R. Ro. (1992). Metodología de la investigación aplicada al turismo: casos prácticos. México: Trillas.

Cohen, E. (1972). Toward a Sociology of International Tourism. Social Research. 39 (1),

Cohen, E. (1979). Rethinking the sociology of Tourism. Annals of Tourism Research, 6(1), Jan./Mar.

Comic, D. K. (1989). Tourism as a subject of philosophical reflection. Revue de Tourisme. AIEST, n. 2, 1989, pp. 6-13. 
Conde Gaxiola, N. (2008a). ¿Es posible una teoría hermenéutica dialéctica en el estudio del turismo? Teoría y Praxis, 5, 197-211.

Conde Gaxiola, N. (2008b). Hermenéutica dialéctica transformacional aplicada al turismo, el derecho y las ciencias sociales. México: Instituto Politécnico Nacional.

Cooper. C., Fletcher, J., Gilbert, D., \& Wanhill, S. (1993). Tourism: Principles and Practices. London: Pitman.

Cuervo, R. S. (1967). El turismo como medio de comunicación humana. México-DF: Departamento de Turismo do Governo do México.

Dann, G. M. S. (2011). Anglophone hegemony in tourism studies today. Enlightening Tourism. A Pathmaking Journal, 01, pp. 1-30.

Darbellay, F.; Stock, M.(2012)Tourism as complex interdisciplinary research object, Annals of Tourism Research, 39 , pp. 441-458.

Defert, P. (1966). Quelques referentes historiques de tourisme moderne. Berna : AIEST Editions Gurten.

Dencker, A. de F. M. (1998). Métodos e técnicas de pesquisa em turismo. São Paulo: Futura.

Dolling, L. M. (2003). Dialogue as praxis: philosophical hermeneutics, historical epistemology, and truth. In: Gould, C. C. Constructivism and practice: toward a historical epistemology. Oxford: Rowman \& Littlefield. pp. 33-46.

Fernández Fúster, L. (1978). Teoría y técnica del turismo. Tomo I. Madrid: Editora Nacional.

Ferreira, L. R. (2008). O turismo sexual e a comunicação - um olhar hermenêutico sobre as relações entre visitantes e visitadas. Revista Brasileira de Pesquisa em Turismo, 2(2),pp. 84-112.

Feyerabend, P. (1975). Against method. New York: New Left Books.

Foulquié, P., \& Saint-Jean, R. (1962). Dictionnaire de la langue philosophique. Paris: Presses Universitaires de France.

Franklin, A. (2004). Tourism as an Ordering: Towards a New Ontology of Tourism. Tourist Studies, 4 (3), pp. 277-301.

Hessen, J. (2003). Teoria do conhecimento. 2.ed. São Paulo: Martins Fontes.

Hirst, P. (1965). Liberal education and the nature of knowledge. In: Philosophical Analysis and Education, R. D. Archambault, ed. Henley: Routledge \& Kegan Paul. pp. 113-140

Hirst, P. (1974). Knowledge and the Curriculum. London: Routledge.

Hirst, P. (1993). Education, knowledge and pratices. In: Beyond liberal education. Barrow, R \& White, P. (Eds.). London: Routledge. pp. 184-199.

Holden, A. (2011). Relevance and insights. The relationship of the social sciences with tourism studies. In: 
Advancing the Social Science of Tourism Conference. University of Surrey, 28 de junho a 01 de julho.

Hunziker, W., Krapf, K. (1942). Grundriss der Allgemeinen Fremdenverkehrslehre. Zürich: Polygraphischer Verlag AG.

Ingram, G. (2002). Motivations of farm tourism hosts and guests in the South West tapestry Region, Western Australia: A phenomenological study. The Indo-Pacific Journal of Phenomenology, 2(1), pp. 1-12, April.

Jafari, J. (2001). Enciclopedia del turismo. Síntesis. Madrid.

Japiassu, H. (1979). Introdução ao pensamento epistemológico. 3. ed. Rio de Janeiro: Francisco Alves.

Jovicic, Z. (1975). Pou et contre la tourismologie comme discipline scientifique distincte. En : Le bilan des dernieres 25 ans de la recherche touristique. AIEST. St. Gall. Edition Gurten. Berna.

Jovicic, Z. (1988). A plea for tourismological theory and methodology. Tourism Review, 43(3), pp. 2-5, jul./set.

Kant, I. (2003). Crítica da razão pura. São Paulo: Martin Claret.

Krippendorf, J. (1984). Die Ferienmenschen: fur ein neues Verstandnis von Freizeit und Reisen. Zurich: O. Fussli.

Kuhn, T. (2006). La estructura de las revoluciones científicas. México: F.C.E.

Lakatos, I. (1970). History of science and its rational reconstructions. PSA: Proceedings of the Biennial Meeting of the Philosophy of Science Association, Vol. 1970, pp. 91-136. Stable URL: http://links.jstor.org/sici?sici=0270-8647\%281970\%291970\%3C91\%3AHOSAIR\%3E2.0.CO\%3B2-H

Lakatos, I., \& Musgrave, A. (1970). Criticism and the growth of knowledge. Vol. 4. Proceedings of the International Colloquium in the Philosophy of Science, London, 1965, International Colloquium in the Philosophy of Science Studies in logic and the foundations of mathematics. 1970.

Lalande, A. (1999). Vocabulário Técnico e Crítico de Filosofia. São Paulo: Martins Fontes.

Laudan, L. (2011). O progresso e seus problemas: rumo a uma teoria do crescimento científico. Trad. Roberto Leal Ferreira. São Paulo: Editora Unesp.

Leiper, N. (1979). The framework of tourism: towards a definition of tourism, tourist, and the tourist industry. Annals of Tourism Research, 6(4), pp. 390-407, out./dez.

Leiper, N. (1981). Towards a cohesive curriculum in tourism: the case for a distinct discipline. Annals of Tourism Research, 8, pp. 69-84.

Leiper, N. (1995). Tourism management. Collingwood-Victoria: RMIT Press.

Leiper, N. (2000). An emerging discipline. Annals of Tourism Research. 27(3), pp. 805-809, July 2000. 
Lipovetsky, G. (2005). A era do vazio. Ensaios sobre o individualismo contemporâneo. Barueri-São Paulo: Manole.

Lohmann, G.; Panosso Netto, A. (2008). Teoria do turismo: conceitos, modelos e sistemas. São Paulo: Aleph.

Lyotard, J.-F. (1967). A fenomenologia. Lisboa: Edições 70.

MacCannell, D. (1976). The tourist. A new theory of the leisure class. New York: Schoken Books.

Magee, B. (1974). As ideias de Popper. São Paulo: Cultrix and Editora da Universidade de São Paulo.

Marioli, A. P. (2002). Ecoturismo em unidades de conservação: o método fenomenológico aplicado ao Parque Estadual da Cantareira. Unpublished máster dissertation, Universidade de São Paulo, São PauloBrazil.

Martínez, A. de J. J. (2011). De lo global a lo local: las cadenas hoteleras y la región de Cancún - Riviera Maya. In: Mullor, E. C., \& Blázquez, M. (Eds.). Turismo placebo: nueva colonización turística: Del Mediterráneo a Mesoamérica y El Caribe. Lógicas espaciales del capital turístico. Manágua-Nicarágua: EDISA, pp. 251-274.

Masberg, B. A., \& Silverman, L. H. (1996). Visitor experiences at heritage sites: A phenomenological approach. Journal of Travel Research, 34(4), pp.20-25.

Maturana, H. R. (1990). Biología de la cognición y epistemología. Temuco: Ediciones Universidad de la Frontera.

Maturana, H. R.; Varela, Francisco J. (2004). A árvore do conhecimento. As bases biológicas da compreensão humana. São Paulo: Palas Athenas.

Miguélez, R. (1977). Epistemología y ciencias sociales y humanas. Centro de Investigaciones de filosofía de la ciencia y del lenguaje. UNAM. México.

Millennium Development Goals: http://www.un.org/millenniumgoals (Visited May 19, 2012).

Molina, S. (1991). Conceptualización del turismo. México: Limusa.

Mora, J. F. (1964). Diccionario de Filosofía. 5.ed. Buenos Aires: Editorial Sudamericana de Buenos Aires.

Morin, E. (1996). O problema epistemológico da complexidade. Lisboa: Publicações Europa-América.

Morin, E. (1999). O método, vol. 3. O conhecimento do conhecimento. Porto Alegre: Sulina.

Mullor, E. C., \& Blázquez, M. (Eds.). (2011). Turismo placebo: nueva colonización turística: Del Mediterráneo a Mesoamérica y El Caribe. Lógicas espaciales del capital turístico. Manágua: EDISA, 2011.

Nash, D. (1977). Tourism as a form of Imperialism. In: Hosts and Guests: The Anthropology of Tourism, Smith, V. L. (Ed.) Philadelphia: The University of Pennsylvania Press. pp. 33-47. 
Organização Mundial do Turismo. (2001). Introdução ao Turismo. São Paulo: Roca.

Ouriques, R. H. (1998). Turismo em Florianópolis. Uma crítica à indústria pós-moderna. Florianópolis: Editora da UFSC.

Panosso Netto, A. (2005). Filosofia do turismo: teoria e epistemologia. São Paulo: Aleph.

Panosso Netto, A. (2011). Filosofia do turismo: teoria e epistemologia. 2.ed. São Paulo: Aleph.

Panosso Netto, A. Noguero, F. T.; Jäger, M. (2011). Por uma visão crítica nos estudos turísticos. Turismo em Análise. 22(3), pp. 539-560.

Patterson, M. E., Watson, A. E., Williams, D. R., \& Roggenbuck, J. R. (1998). Hermeneutic Approach to Studying the Nature of Wilderness Experiences. Journal of Leisure Research, 30(4), pp. 423-452.

Pernecky, T. \& Jamal, T. (2010). (Hermeneutic) Phenomenology in tourism studies. Annals of Tourism Research, 37(4),pp. 1.055-1.075, out.

Phillimore, J.; Goodson, L. (Eds.). (2004). Qualitative research in tourism. Ontologies, epistemologies and methodologies. London: Routledge.

Popper, K. (2003). A lógica da investigação científica. São Paulo: Cultrix and EDUSP.

Popper, K. (2008). Busca inacabada. Autobiografia intelectual. Lisboa.

Runes, D. D. (1981). Diccionario de Filosofía. Ed. Grijalbo. México.

Russell, N. (1958). Patterns of discovery: an inquiry into the conceptual foundations of science. CUP Archive.Santos, B. de S.; Paula, M. (Orgs.) (2009). Epistemologias do sul. Coimbra: Edições Almedina.

Santos, C. A. \& Yan, C. (2010). Genealogical tourism: a phenomenological examination. Journal of Travel Research, 49(1), pp. 56-67.

Sessa, A. (1985). La scienza dei sistemi per lo sviluppo del turismo. Roma: Agnesotti.

Spode, H. (1993). Historische Tourismusforschung. In Hahn, H., \& Kagelmann, H. J. (Eds.). Tourismuspsychologie und Tourismussoziologie. Handbuch zur Tourismuswissenschaft (pp. 27-29). München: Oldenbourg.

Steup, M. (2011). Epistemology. The Stanford Encyclopedia of Philosophy (Winter 2011 Edition), Edward N. Zalta (ed.), URL $=<$ http://plato.stanford.edu/archives/win2011/entries/epistemology/>.

Stich, S. (1998). Reflective equilibrium, analytic epistemology and the problem of cognitive diversity, p. 95110. In: DePaul, M. R. \& Ramsey, W. M. (1998). Rethinking Intuition: The Psychology of Intuition and Its Role in Philosophical Inquiry. Oxford: Rowman and Littlefield.

Sustainable Tourism for Eliminating Poverty: http://www.unwtostep.org (Visited May 16, 2012).

Szarycz, G. S. (2008). Cruising, freighter-style: a phenomenological exploration of tourist recollections of a passenger freighter travel experience. International Journal of Tourism Research, 10 (3), pp.259-269. 
Szarycz, G. S. (2009). Some issues in tourism research phenomenology: A commentary. Current Issues in Tourism, 12 (1), pp. 47-58.

Toulmin, S. (1972). Human understanding. Oxford: Clarendon Press.

Tribe, J. (1997). The indiscipline of tourism. Annals of Tourism Research, 24(3), pp.638-657.

Tribe, J. (2000). Indisciplined and Unsubstantiated. Annals of Tourism Research, 27(3),pp.809-813.

Tribe, J. (2004). Knowing about tourism. Epistemological issues. In Phillimore, J. \& Goodson, L. (Eds.), Qualitative research in tourism. Ontologies, epistemologies and methodologies London: Routledge. pp. 4662.

Tribe, J. (2008). Tourism: A Critical Business. Journal of Travel Research, 46, pp. 245-255.

Vasconcellos, M.J. E. de. (2002). Pensamento sistêmico: o novo paradigma da ciência. Campinas: Papirus.

Wittgenstein, L. (2008). Tratactus Lógico-Philosophicus. 3.ed. São Paulo: EDUSP.

Young, G. (1973). Tourism: Blessing or Blight. Harmondsworth. Penguin Books.

Artigo recebido em: 17/02/2014.

Artigo aprovado em: 28/03/2014. 